Review

\title{
A Scientometric Review of Smart Construction Site in Construction Engineering and Management: Analysis and Visualization
}

\author{
Honglei Liu ${ }^{1,2}$, Jiule Song ${ }^{2,3,4, *}$ and Guangbin Wang ${ }^{2}$ \\ 1 Department of Construction Management, Changshu Institute of Technology, Changshu 215500, China; \\ 666honglei@163.com \\ 2 Department of Construction Management and Real Estate, School of Economics and Management, \\ Tongji University, Shanghai 200092, China; gb_wang@tongji.edu.cn \\ 3 Shanghai Tunnel Engineering Co. (Singapore) Pte Ltd., Singapore 049712, Singapore \\ 4 STEC SUCG International Engineering Co., Ltd., Shanghai 200032, China \\ * Correspondence: 1310374@tongji.edu.cn
}

check for updates

Citation: Liu, H.; Song, J.; Wang, G. A Scientometric Review of Smart Construction Site in Construction Engineering and Management: Analysis and Visualization. Sustainability 2021, 13, 8860. https:// doi.org/10.3390/su13168860

Academic Editors: Shah Kwok Wei, Michael Yit Lin Chew, Evelyn Ai Lin Teo, Vishal Kumar, Ghasan Fahim Huseien and Marc A. Rosen

Received: 23 May 2021

Accepted: 4 August 2021

Published: 8 August 2021

Publisher's Note: MDPI stays neutral with regard to jurisdictional claims in published maps and institutional affiliations.

Copyright: (c) 2021 by the authors. Licensee MDPI, Basel, Switzerland. This article is an open access article distributed under the terms and conditions of the Creative Commons Attribution (CC BY) license (https:// creativecommons.org/licenses/by/ $4.0 /)$.

\begin{abstract}
With the extensive development and application of information technologies in construction engineering and management (CEM), the construction site is experiencing a rapid digital revolution and transformation. Since smart construction site has become the current research trend and one of the most hot topics, thus this study adopted an integrated bibliometric approach and quantitative analysis to explore the global research on smart construction site. As it is indicated in the content, the bibliometric and scientometric method-based literature review was carried out in this study. To be specific, the co-citation analysis in terms of author, document, and journal; the collaboration analysis in terms of authorship, institutions, and country/region; and category analysis, as well as cluster analysis and burst analysis were conducted based on 2206 peer-reviewed academic papers, which were published from January 2000 to February 2021. It is found that there has been an explosion of relevant publications especially in the past 10 years along with the changing of keywords from flexibility approach to information technologies, 3D reconstruction, IoT technologies, virtual reality, and others. Moreover, the results indicated that the collaborations and cooperation among different institutions, countries, and authors are not close enough, and the most significant research and development in smart construction occurred primarily in the USA, China, and England. Additionally, the smart construction site's relevant research in terms of publication of quantity was doubled every five years. In addition, the smart construction site relevant research has gradually changed from the traditional project performance associated indicators to smart simulation applications and scenes. Lastly, implementation and management-related concerns about smart construction sites are discussed with seven topics. This study provides researchers and practitioners not merely with an in-depth understanding of the characters and also the trend of smart construction site research in the construction engineering and management field.
\end{abstract}

Keywords: smart construction site; scientometric; visualization; research trend

\section{Introduction}

Smart construction site (SCS), which is also known as intelligent construction site, is composed of a system of seamlessly networked sensors, displays, and computational elements with embedded intelligence and advance digital application [1]. It has been attracting increasing interest and applications in the construction industry worldwide. To highlight the adoption and benefits of SCS for construction engineering and management (CEM), a large number of applications and various research on SCS have been conducted and published in the recent decade. Some practitioners focus on the economic benefits of SCS [2,3], while others concentrate on the technical issues relating to [4,5]. Conventionally 
and obviously, CEM involves construction-related tasks, processes, issues, and human collaboration factors SCS [6], thus SCS application in CEM is fraught with inherent complexity. Therefore, various effects associated with SCS have been reported, such as cost and time savings [7], improving productivity and safety of construction projects [3], facilitate the position detection of construction elements [8], and risk mitigation and digitalization, as well as computer vision [9].

In the last decade, more emerging technologies have been introduced in the construction industry. For instance, Jiang et al. [10] proposed a cyber-physical system-based site safety management system and categorized it into CSC. The involved aspects are personnel and mechanical positioning, environmental monitoring, and other risks on site. By explore and define the concept of digital skin, Edirisinghe [1] believes the future smart construction site will be pervasive, context-aware, and embedded with intelligence through the integration of hardware components, communication technologies, and software, middleware/applications. Pan and Zhang [9] presented a review of artificial intelligence (AI) implementation, advantages, and research in the existing CEM approach, and seven essential directions of future researches are highlighted that facilitate AI in CEM. Štefanič and Stankovski [11] identified and summarized the emerging smart construction applications, including construction site management, construction monitoring, early warning, resource and assets management, and safety at work. However, limited efforts have been made to visualize and concentrate on the keywords, authors/institutions/universities, cooperation networks of existing publications, nor the management-related problems that initiated due to the use of smart technologies on site.

Even though there are many scholars discussed digitalization in the Architecture, Engineering, and Construction (AEC) industry in terms of industry 4.0 and/or construction 4.0 [12-15], and some of them even used industry/construction 4.0 with smart construction site synonymously [16], the authors believe Industry 4.0 and/or Construction 4.0 is a much broader field than the topic discussed in this study-smart construction site. For instance, Alaoul et al. [17] indicated that Industry 4.0 can be described as the trend towards digitalization, automation, and widespread use of information and communication technologies in the AEC industry; Hallward and Nayyar [18] believed Industry 4.0 is to digitize industrial processes to accomplish an adaptive yet extensive production and services network. Sawhney et al. [19] define Construction 4.0 as a "transformative framework" where three transformations take place: industrial production and construction, cyber-physical systems, and digital technologies. Thus, it can be somehow inappropriate cited to say that a construction site utilizing an Industry 4.0 and/or Construction 4.0 technology could be regarded as a smart construction site. A very limited number of studies was found on the review of smart construction site in construction management and engineering, which is consistent with other studies. For example, Martinez, P. et al. [20] only reviewed the computer vision application in construction engineering and management; El-Sayegh et al. [21] just reviewed the benefits, challenges, and risks of 3D printing in construction; Štefanič and Stankovski [11] simply elaborated the emerging smart construction application in areas of construction monitoring, safety at work and early disaster warning, etc. The existing publications mostly perspective their results from a sub/narrowed direction rather than from a comprehensive view of technologies within the CEM industry. Besides, the keywords, authors, institutions/universities, countries, as well as cooperation networks among the publications were ignored. That leads us to the conclusion that the smart construction site is still in the process of investigation and there is a need for further exploration. To tackle these existing limitations of current studies, this study aims to conduct a scientometric review on SCS and gain an overview of this topic span within the year 2000-2020, while in order to enclose as many latest papers as possible, publications from January and February 2021 were also included in this study. Scientometric is the field of study that concerns itself with measuring and analyzing scholarly literature, it's a method of research that includes qualitative, quantitative, and computational approaches. CiteSpace nowadays is one of the most popular software packages for scientometric, which could explore and visualize 
the impact of authors, journals, and institutes, understanding of scientific citations, etc. Additionally, it has been adopted in many domains, e.g., Zhao [22] and Pan and Zhang [9] in architecture, engineering, and construction (AEC) industry, Chen, Dubin et al. [23] in the medical field, and Olawumi and Chan [24] in sustainability, etc. The results could present the practitioners and researchers with a better understanding of the recent status of SCS research in the world and help to discover the current research hotspots in CEM. The relationships among the different topics could also be revealed in a more intuitive shape. Other than the scientometric analysis and visualization, a discussion within seven topics was also presented in this study.

The structure of this study is organized as follows: the general understanding of smart construction sites is presented in Section 1. In Section 2, the data collection and methodology were introduced in order to provide a comprehensive literature review and content analysis. In Section 3, the results of the scientometric analysis were illustrated. The discussion organized in Section 4 presents the current research status, SCM-related issues, and future research directions. Finally, conclusions are stated in the last section.

\section{Data Collection and Research Methodology}

\subsection{Data Collection}

Bibliographic data for this scientometric review was solely collected from the Web of Science core collection database. This is because, first, as mentioned in this paper, the authors used CiteSpace as the tool to do the scientometric analysis, as CiteSpace is a Web of Science oriented tool that suits the Web of Science database very well. The authors cannot guarantee the quality of the data converted from other databases. Second, the authors conducted searches with keywords "smart construction site" in Compendex, Scopus, and Google Scholar, and a comparison of the results between the above-mentioned database and Web of Science were conducted also. It was found that there are many duplicated publications among them. Therefore, the authors did not include the results from Compendex, etc. Third, by referring to the existing published paper (which used the scientometric method), most of the authors also choose Web of Science as the sourcing of data. Furthermore, to be more specific, the core databases this paper used are Science Citation Index Expanded (SCI-EXPANDED), Social Sciences Citation Index (SSCI), and Arts \& Humanities Citation Index (A\&HCI). As it is indicated by Xue, Shen et al. [25], peer-reviewed articles are considered to have better academic standing, thus in this research, only peer-reviewed articles were selected for analysis, while review, editorial, and proceedings papers were excluded. Edirisinghe's [1] study was referred for the selection of search terms, and then a pre-analysis and comparison were conducted to refine the terms. The following searching terms for this study were used: topic = " smart construction site", "intelligent construction site", "artificial intelligence" OR "AI" OR "computational intelligence", "augmented reality" OR "AR", "sensors", "internet of things", "tracking", "locating" OR "localizing" OR "location", "monitoring" OR "real-time", "information technology") AND topic = ("construction management" OR "civil engineering" OR "construction project" OR "construction industry" OR "construction engineering"). The timespan in Web of Science is from 2000 to 2021 .

The advanced refine option Web of Science Categories was also utilized to exclude the non-construction industry paper. To be specific, the irrelevant categories/industry (e.g., physics nuclear, agricultural engineering, medicine, etc.) were excluded from the result. Finally, a total of 2206 bibliographic data mostly related to the study area are collected in February 2021, which will be discussed below.

\subsection{Analysis of Publications}

Figure 1 evidently expressed the upward tendency of the annual number of SCSrelated publications during 2000-2021, which, indicating the use of smart construction site technologies in construction engineering and management, is becoming a remarkable topic in recent years. At a 5-year interval, the number of SCS-relevant publications shows an 
exponential increase in the past 20 years, starting to boost in 2010. For the year of 2000-2004, the number of published papers is 127 (which accounted $5.8 \%$ of total published paper); for the year of 2005-2009, it is 252 (11.4\%); for the year of 2010-2014, it is $525(23.8 \%)$; and for the year of 2015-2019, it is 947 (42.9\%). Thus, it is reasonable to estimate that the number of relevant publications can increase to 1800 at the end of 2024. Under the expectation of building a pervasive construction site in the future, SCS solutions are attracting more and more attention from practitioners and scholars.

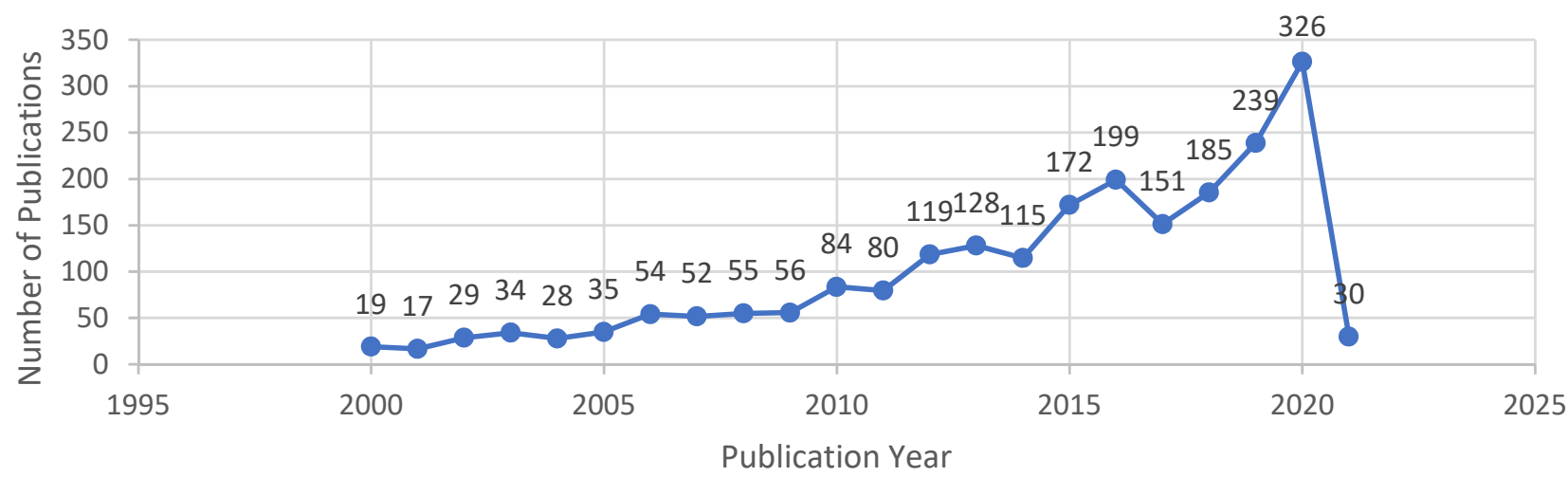

Figure 1. Amount of SCS-relevant publications in CEM during 2000-2021 (For the dropped number of publications in 2021, it is because the data only covers January and February of 2021).

The institutions and journals that dedicated and published most of the SCS-relevant papers were identified in this study. Figure 2 visualized the institutions that published more than 30 SCS-related papers during 2000-2021, and Figure 3 visualized the top 10 journals that published more than 30 SCS-related papers. To put it another way, those journals and institutions contribute much to SCS-related research and studies. As it can be seen from Figure 2, Hong Kong Polytech University is comparatively the main SCS research institution, followed by Georgia Inst Technol, City Univ Hong Kong, Tsinghua Univ, Queensland Univ Technol, etc.

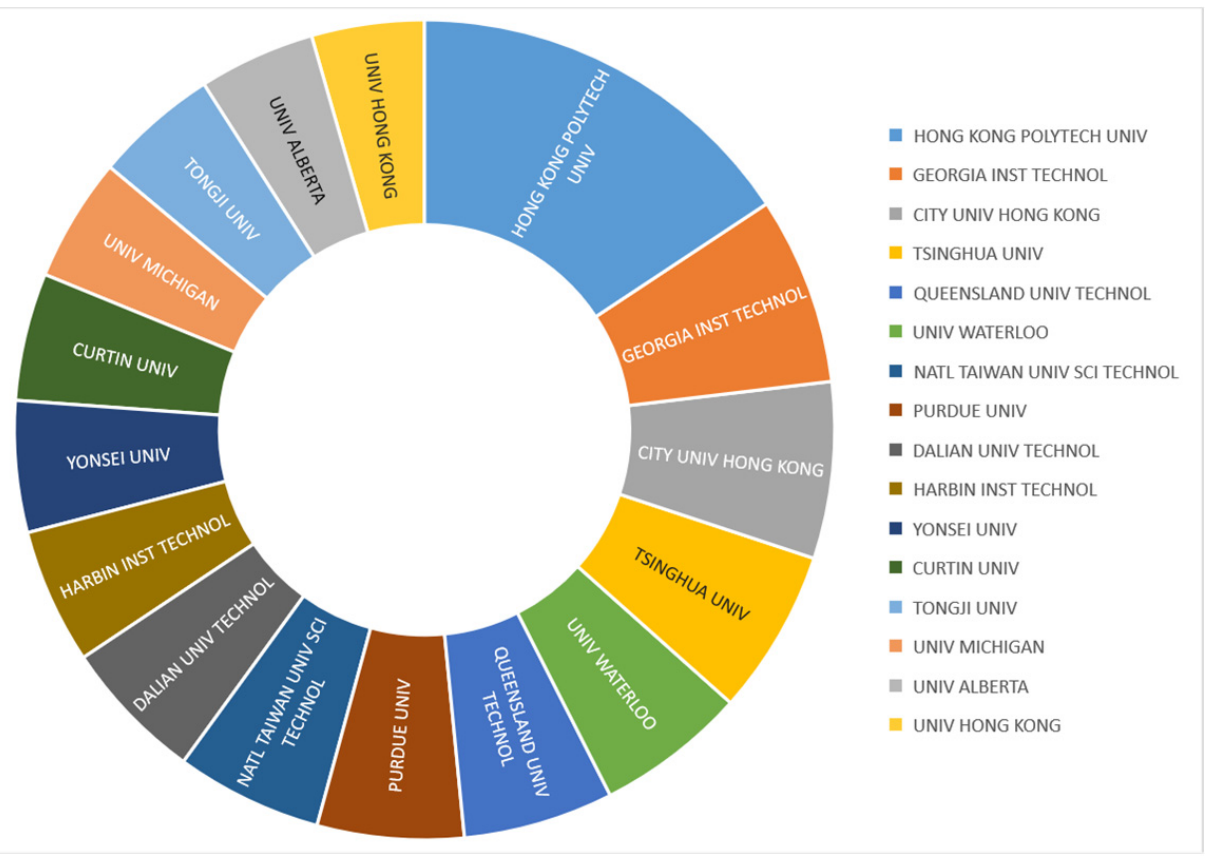

Figure 2. Institutions with more than 30 papers published in 2000-2021. 


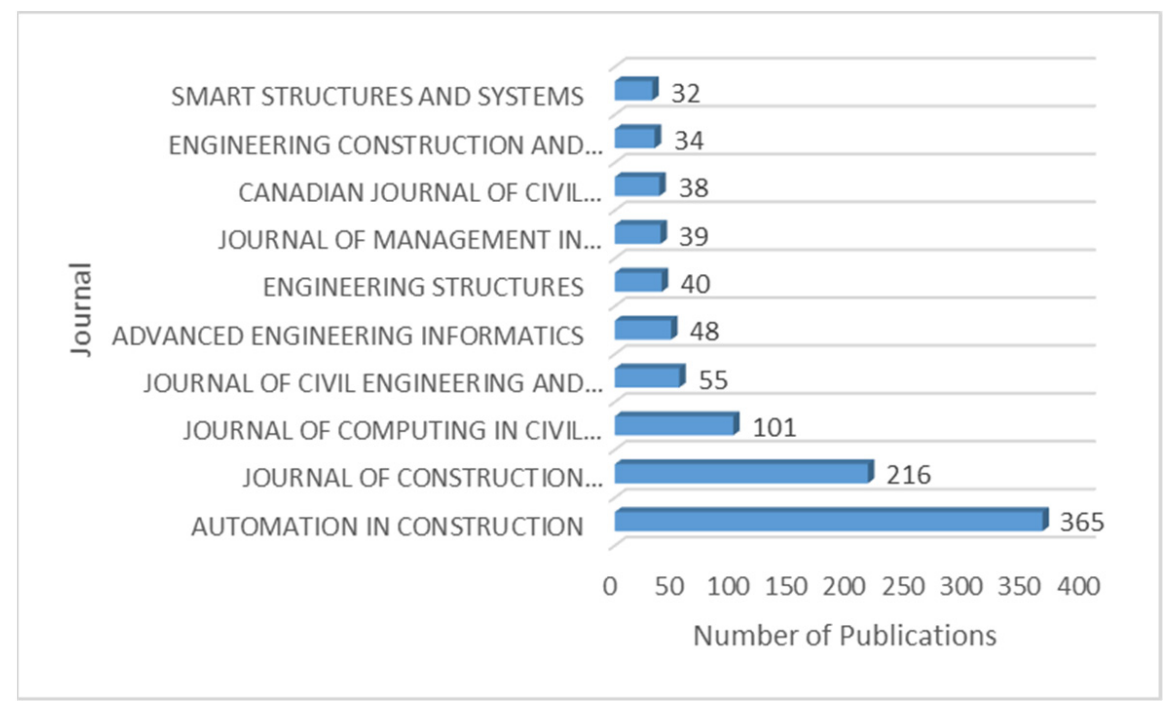

Figure 3. Journals with more than 30 papers published in 2000-2021.

Automation in Construction (AIC), Journal of Construction Engineering and Management (JCEM), and Journal of Computing in Civil Engineering (JCCE) own the majority of the publications in the SCS field, with 365 papers in AIC, 216 in JCEM, and 101 in JCCE. They accounted for $30.92 \%$ of the papers this study collected. With the inclusion of AIC, JCEM, and JCCE, the 10 journals in Figure 3 are all Q1 journals in recent years, thus their importance can be validated.

In addition to the institutions and journals, the countries/regions that published most of the SCS papers were also identified in this study. According to the data this research collected, there are 90 countries/regions that published 2206 papers in terms of the smart construction site. Researchers from the United States of America (USA), People's Republic of China (PRC), England, Australia, South Korea, Canada, and Taiwan occupy most of the publications (which accounted for $60.6 \%$ of the total) in this SCS fields.

\subsection{Research Methodology}

The software package, CiteSpace 5.7.R4, is a Java-based scientometric tool that was adopted to do the scientometric analysis in this study. CiteSpace has been well acknowledged by the various graphs and strong logical visualization to knowledge domains [26]. It could help to discover the implied meaning hidden in a disorganized data and trace the trends and frontiers of its development [27].

By referring to the existing research $[9,16,22]$, three categories of bibliometric analysis (e.g., in terms of co-authorship analysis, network of subject category and keywords, document co-citation analysis, etc.) were adopted to do the scientometric research in this study. The co-category analysis is to highlight the researches in the same category; co-word analysis is used to analyze word co-occurrences basis keywords and/or terms; co-citation analysis is used to recognize the co-cited authors, co-cited journals, and co-cited articles; cluster analysis is used to recognize the research front and reveal latent topics. Co-occurrence analysis (author co-occurrence, institution, and country co-occurrence) is also performed in this study to reveal the research collaboration maps.

\section{Results}

\subsection{Research Collaboration Network}

Research collaboration is the scheme that researchers working together to achieve a goal of producing new scientific knowledge [28]. As it is indicated by Wuchty, Jones et al. [29], the process of knowledge creation has fundamentally changed that research is increasingly carried out in teams rather than in solo authors in the knowledge production. 
Therefore, the collaboration research was first carried out in terms of co-authors, the network of institutions, and the network of country/regions in this study.

\subsubsection{Co-Authorship}

The visualization of research collaboration in terms of the author was performed in CiteSpace, and the results are shown in Figure 4. This co-authorship network is consisting of 683 nodes and 410 links. Each of the nodes represents an author and the links among the nodes indicating that there is a collaboration between the authors. Moreover, the size of the nodes stands for the number of published articles, and the thickness of the links stands for the strength of the collaboration-ship in a specific year. In the meantime, the density of the co-author network is 0.0018 , which is not relatively tight and thus the cooperation between the authors is not at a high level.

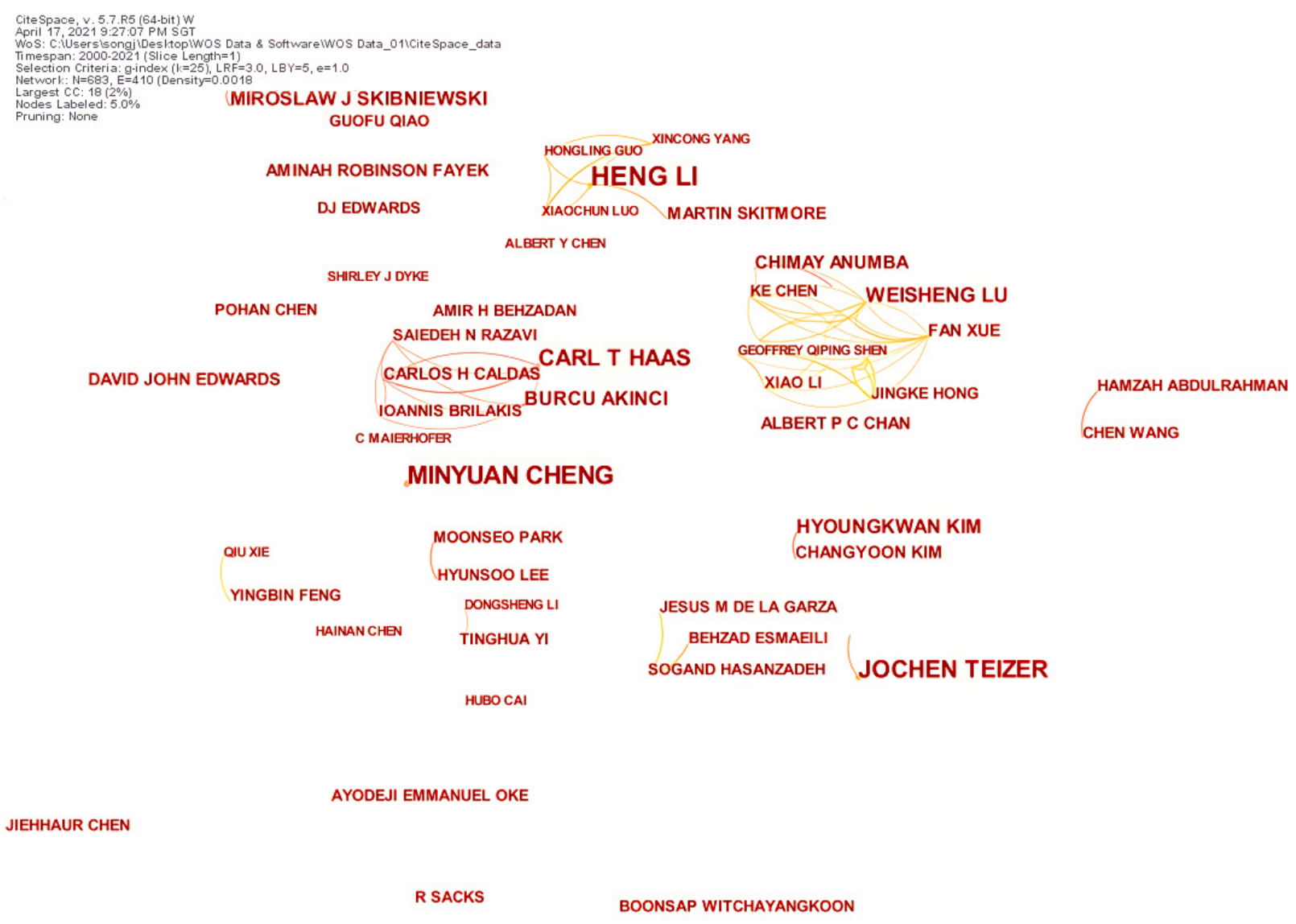

Figure 4. Co-authorship network.

However, there are do existing some highly collaborated authors, e.g., Heng Li (collaborated in 16 records), Minyuan Cheng (collaborated in 15 records), Jochen Teizer (collaborated in 12 records), Carl T Hass (collaborated in 10 records), Weisheng Lu (collaborated in 8 records), Hyoungkwan Kim, Miroslaw J Skibniewwski, and Burcu Akumba (collaborated in 7 records). Additionally, there are some research communities that identified that the prolific authors were usually co-working with many other authors, for instance, the Weisheng Lu, Carl T Haas, and Heng Li community, that the researchers in each community have established a strong collaboration.

\subsubsection{Network of Institution Analysis}

An institution network was produced to identify the contribution of worldwide universities and/or institutions. This network includes 534 nodes and 469 links. The color of the nodes, e.g., red, orange, yellow, green, blue, etc., indicates the different years from 
2021 to 2000, as shown in Figure 5. In addition, the size of the nodes denotes the number of publications of a university/institution in a given year.

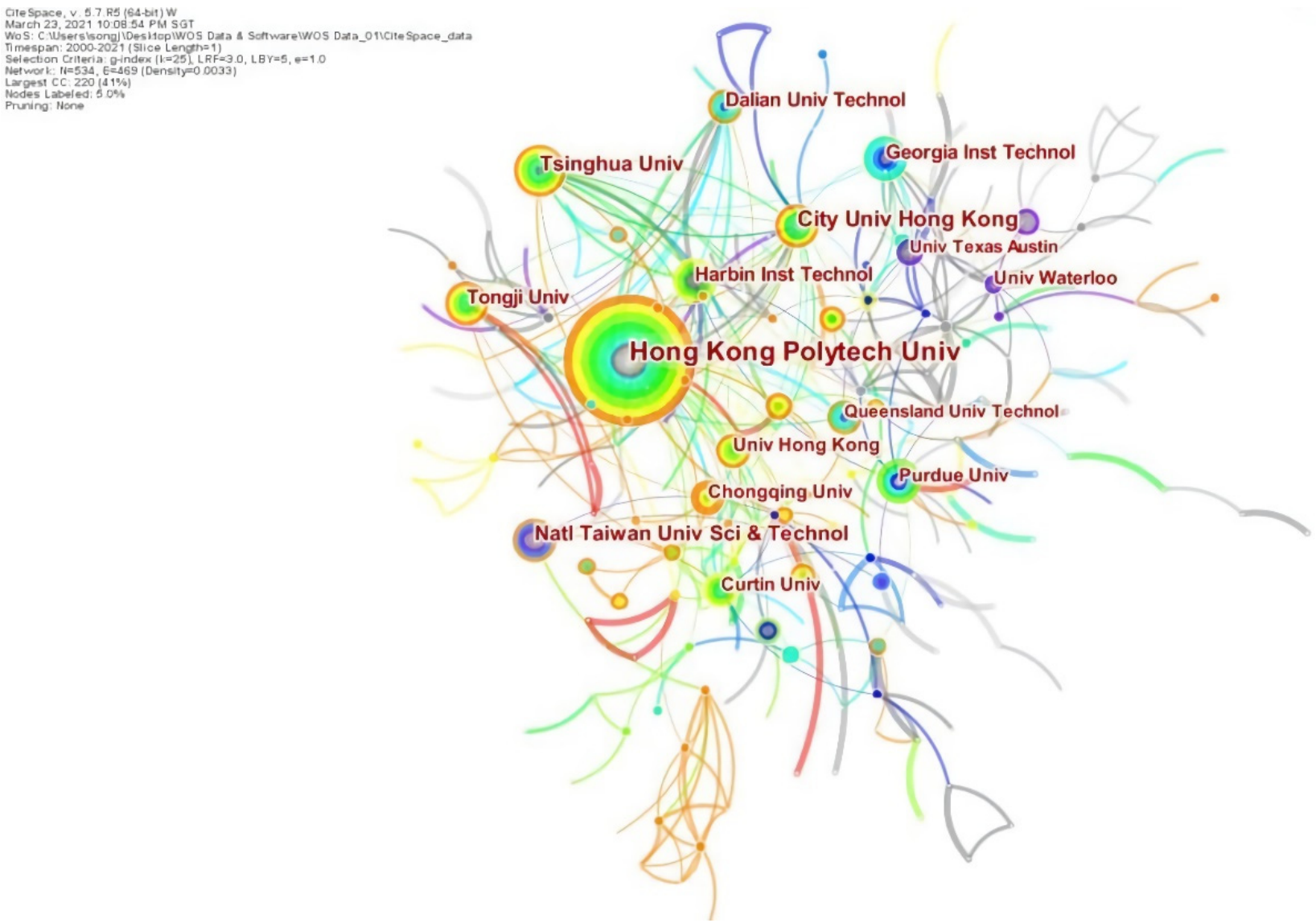

Figure 5. Network of institutions.

As shown in Figure 5, the Hong Kong Polytechnic University (79 publications), City University of Hong Kong (35 publications), Tsinghua University (30 publications), National Taiwan University of Science and Technology (29 publications), Harbin Institute of Technology and Dalian University of Technology (27 publications), Georgia Institute of Technology and Tongji University (25 publications), as well as Chongqing University (22 publications), and Purdue University (21 publications), are the top 10 prolific universities for SCS research around the world. Moreover, most of their publications are identified after the year 2016.

In addition to the number of publications, the node centrality was also calculated, and the partial results are shown in Table 1 . The centrality of the institutions is less than 0.11 , indicating that there is no such institution holding the key position in the network and the collaborations among different institutions are weak in terms of the smart construction site.

Table 1. Centrality of institutions.

\begin{tabular}{cccccc}
\hline No. & Centrality & Institutions & No. & Centrality & Institutions \\
\hline 1 & 0.11 & Hong Kong Polytech Univ & 7 & 0.04 & Purdue Univ \\
\hline 2 & 0.06 & Curtin Univ & 8 & 0.03 & Dalian Univ Technol \\
\hline 3 & 0.06 & Harbin Inst Technol & 9 & 0.03 & Guangzhou Univ \\
\hline 4 & 0.05 & Tsinghua Univ & 10 & 0.03 & Tongji Univ \\
\hline 5 & 0.04 & City Univ Hong Kong & 11 & 0.03 & Univ Illinois \\
\hline 6 & 0.04 & Georgia Inst Technol & 12 & 0.03 & Univ Texas Austin \\
\hline
\end{tabular}




\subsubsection{Network of Co-Country/Region Analysis}

In addition to the co-authorship and co-institution analysis, a co-country/region network was also generated to recognize the collaboration and contributions in terms of country and/or region. As shown in Figure 6, the USA, Peoples Republic of China, England, Australia, South Korea, Canada, and China Taiwan have made most of the publications in SCS. Furthermore, England (centrality $=0.33$ ), USA (centrality $=0.32$ ), France (centrality $=0.22)$, Peoples Republic of China (centrality $=0.18)$, Australia (centrality $=0.15)$, and Canada (centrality $=0.10$ ) nodes were marked with a purple circular in the network, which means they made the essential contributions and bridged most of the countries/regions in SCS related research. In addition, it can be referred from Figure 6 that the USA, England, and People's Republic of China have widely collaborated with other countries/regions, e.g., Iran, Germany, Italy.

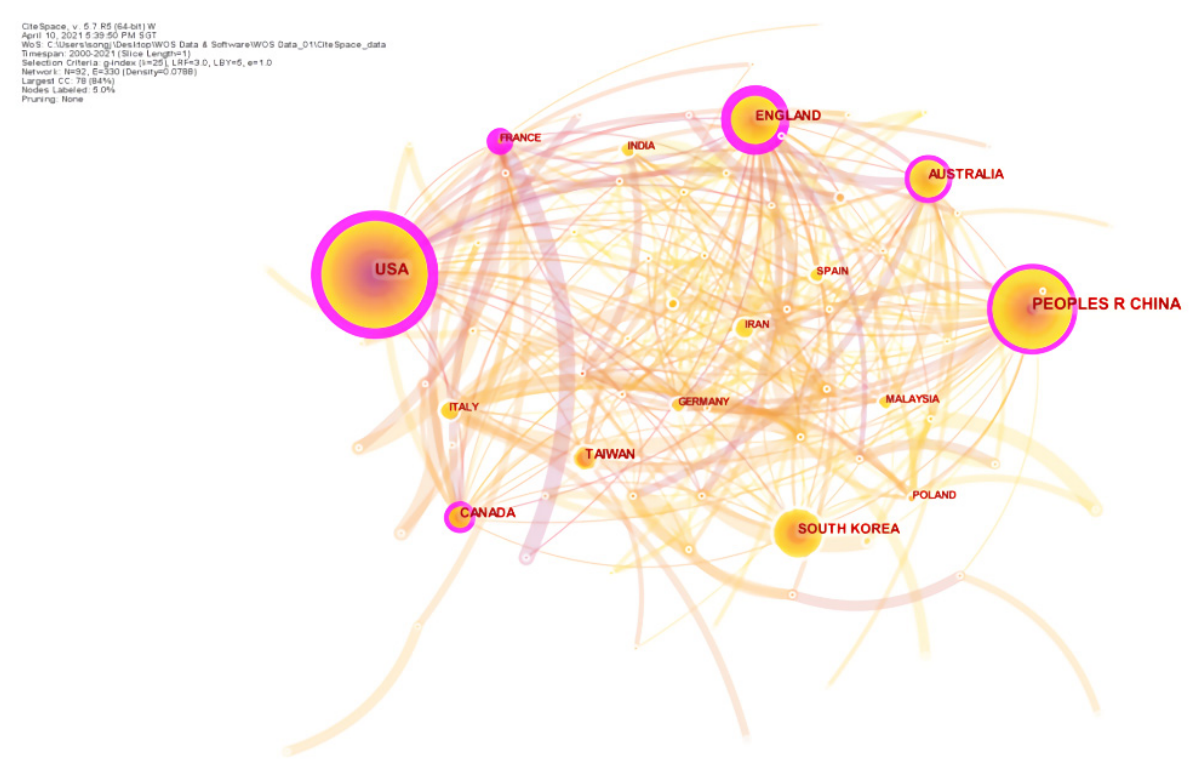

Figure 6. Network of countries/regions.

\subsection{Network of Subject Category and Keywords}

According to different areas of focus, each journal in the Web of Science core database is assigned to one or more subject categories. As it's indicated by Zhao [22], the subject category could be used to analyze the emerging trends in a knowledge domain. Thus, a network of the co-occurring subject was produced in this study, as shown in Figure 7. There are 115 nodes and 607 links. The node size represents the number of publications in each subject category. As it also can be referred from Figure 7, engineering, engineering and civil, construction and building technology, engineering, and industry, as well as computer science are the hottest topics in recent five years' SCS research. This suggested that the potential of smart construction technology in construction and civil had been recognized and attracted increasing attention from researchers. Moreover, the category of engineering, environmental science and ecology, business and economics is highlighted by purple rings, which indicates they are having high betweenness centrality. For instance, engineering (centrality $=0.72$ ), business and economics (centrality $=0.17$ ), computer science (centrality $=0.14)$, and environmental science and ecology (centrality $=0.13)$. They are significantly the connection point and influenced the development of smart construction technologies in SCS research.

Zhang, Yu et al. [30] indicated there are two types of keywords in the Web of Science database, namely Keywords Plus and Authors Keywords, and Keywords Plus is not only more broadly descriptive, but also as effective as Author Keywords in terms of bibliometric analysis. Thus, a co-occurring Author Keywords and Keywords Plus method was used to 
analyze the research topic over time, as shown in Figure 8. The network of co-occurring keywords has nodes and links.
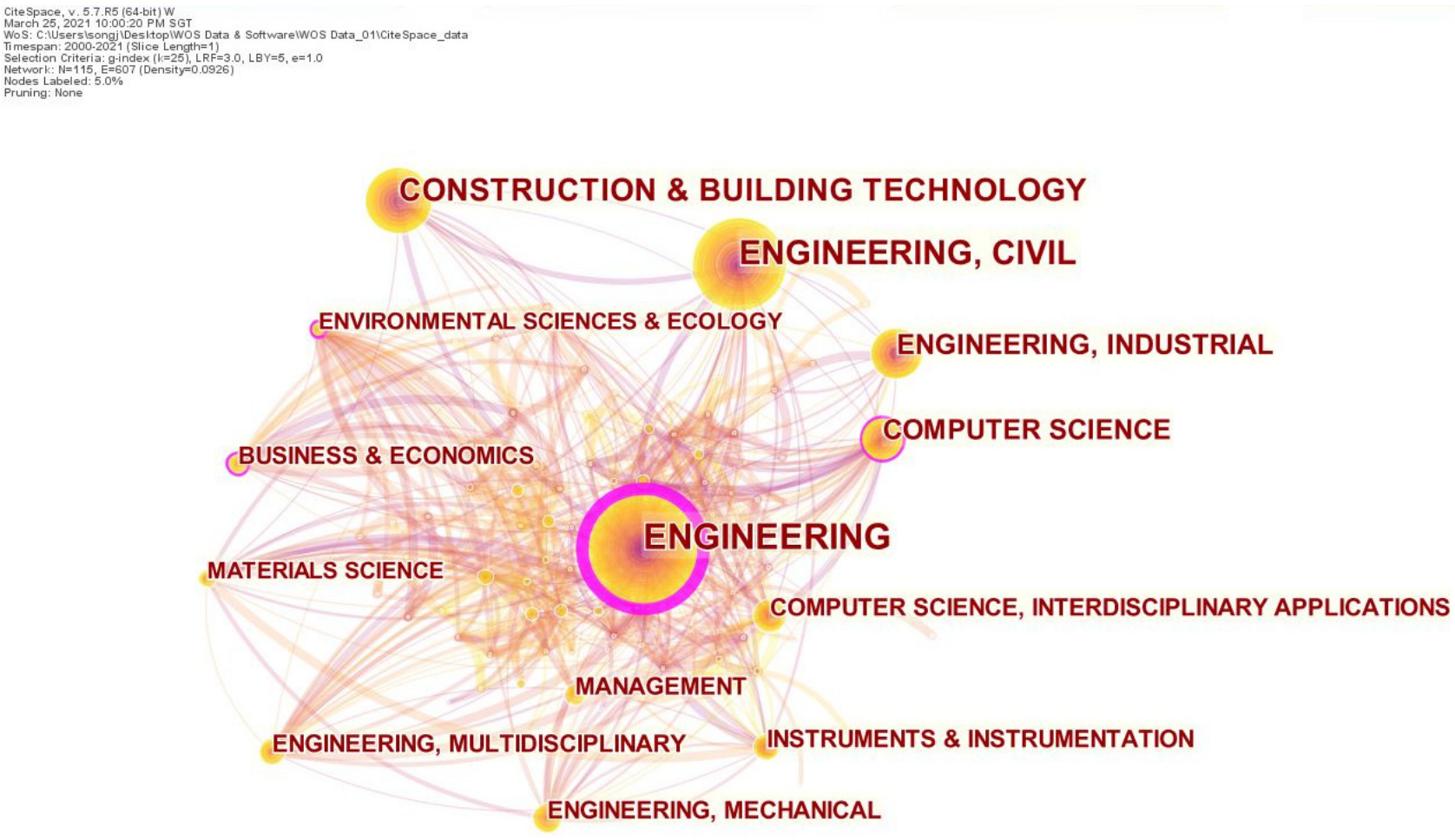

Figure 7. Network of the co-occurring subject.

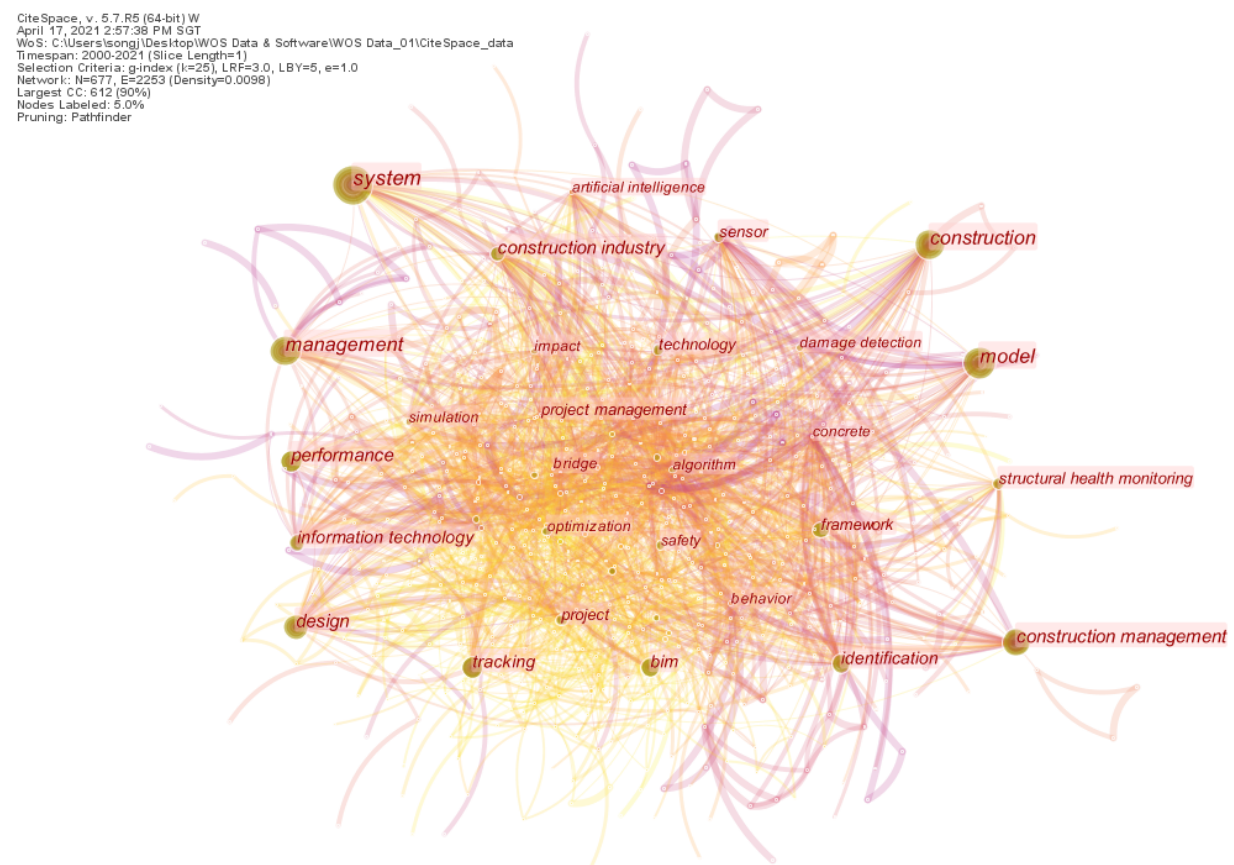

Figure 8. Network of co-occurring keywords.

The node size represents the keywords' occurred frequency in this study. "system" (frequency = 267), "model" (frequency = 240), "management" (frequency = 206), "construction" (frequency = 202), "design" (frequency = 148), "construction management" (fre- 
quency = 136), "construction industry" (frequency = 134), "performance" (frequency =126), "identification" (frequency = 113), "tracking" (frequency = 103), and "information technology" (frequency $=102$ ) are the top 11 high-frequency keywords which have more than 100 co-occurring frequencies. Moreover, among of them, "construction" (centrality $=0.11$ ), "model" and "design" and "construction industry" (centrality = 0.09), and "management" (centrality $=0.07$ ) received relatively high centrality scores. According to the definition of centrality, it can be concluded that they bridged the research of smart construction technology implementation and management in the construction management industry. In addition, the top 5 keywords with the strongest citation burst were also analyzed, and they are "construction management" (strength $=10.21,2006-2013)$, "radio frequency identification" (strength = 8.43, 2007-2014), "sensor" (strength = 7.29, 2005-2009), "information technology" (strength $=7.15,2007-2010)$, and "project management" (strength $=6.8$, 2002-2011). It is indicating that these are topics received the longest duration of attention.

\subsection{Co-Citation Analysis}

Co-citation analysis is a reliable and validated approach for investigating the intellectual structure, and it is an irreplaceable role in scientometric analysis [31]. It is defined as the frequency with which two documents are cited together by other documents [32]. In CiteSpace, three types of co-citation analysis are offered, namely document co-citation, author co-citation, and journal co-citation. Thus, the three types of co-citation networks were generated in this study.

\subsubsection{Author Co-Citation Network}

An author co-citation network is used to illustrate the citation relationships among different authors. A network inclusive of 940 nodes and 4605 links was generated as Figure 9. The node size represents the co-citation numbers of each author, and the links represent indicate a kind of cooperative relationship among different authors. The most co-cited authors were highlighted in Figure 9, they are Teizer, Allread et al. [33] (frequency =117), Li, Ma et al. [34] (frequency = 100), Golparvar-Fard, Peña-Mora et al. [35], and Navon and Berkovich [36] (frequency $=77$ ), and Cheng and Teizer [37] (frequency $=71$ ). Moreover, one node with high centrality (which node is highlighted with purple rings) was identified in the network, and it is Li, Ma et al. [34] (centrality $=0.22$ ). Li, Ma et al. [34] simultaneously occupy the high centrality and high co-citation count, thus, they are to a great extent to have a fundamental influence on the development and evolution of SCS research.

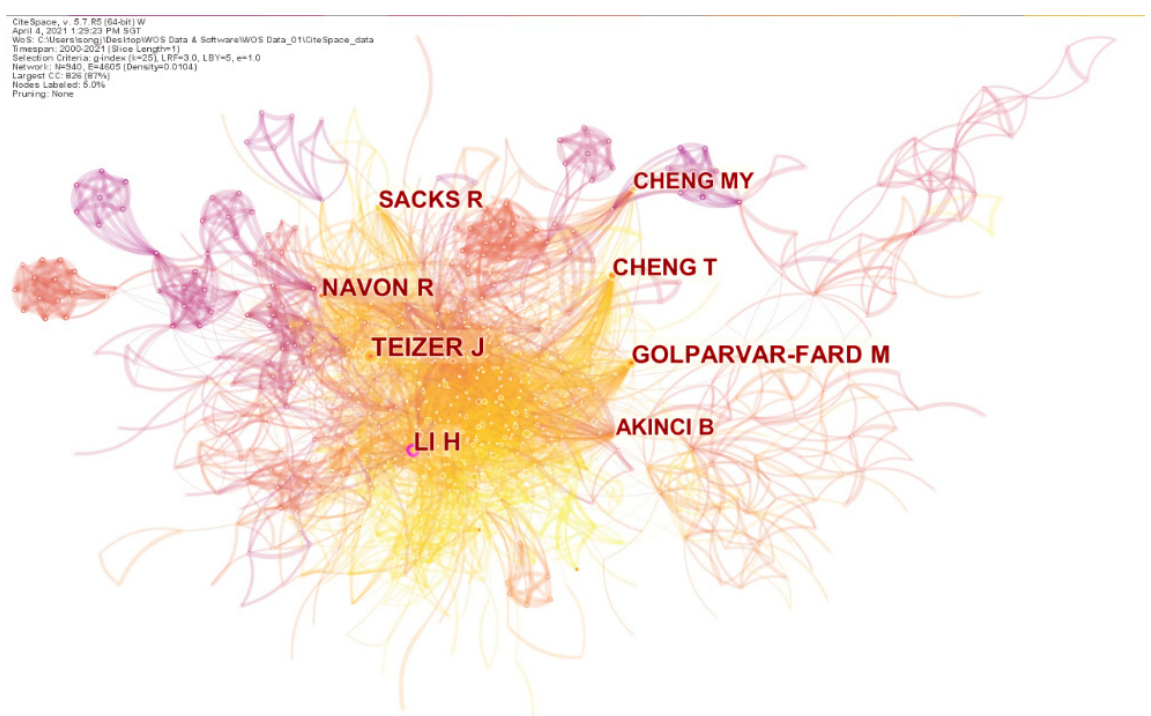

Figure 9. Network of author co-citation. 


\subsubsection{Document Co-Citation Network}

Network of document co-citation was also generated in this study. As stated in Figure 10, there are 920 nodes and 1806 links. Each node stands for an article and is marked with the first author's name and the year of publication, while the node size represents the co-citation frequency of an article. It should be noted that each node size in this network is smaller than 20, except Seo, Han et al. [38] and Cheng and Teizer [37], as they received 22 and 20 co-citations, respectively, followed by Cheng et al. [39] (frequency = 19), Ergen et al. [40] (frequency = 19), Song et al. [41] (frequency = 19). Moreover, Razavi and Haas [42] is the solo node highlighted with a purple ring in the document co-citation network, which means their publication has a high centrality. It can be seen as the major intellectual landmark in SCS research, and thus worth more attention. Razavi and Haas [42] indicated that the automated material tracking and locating on site can significantly impact construction productivity, thus they developed a data fusion model to automatically do identification, location estimation, and dislocation of materials on site. Moreover, 66 documents with strong citation bursts were detected in CiteSpace, and the top five documents are (which sorted by the strength of burst) Song, Haas et al. [41] (strength of burst $=9.87$, 2006-2011), Song, Haas et al. [41] (strength of burst $=4.99,2008-2011$ ), Ergen, Akinci et al. [40] (strength of burst $=9.87,2009-2012$ ), Jaselskis and El-Misalami [43] (strength of burst $=3.29,2006-2021$ ), and Yagi, Arai et al. [44] (strength of burst $=3.60$, 2007-2021). Notably, the citation burst generally starts two or three years after the publication of an article. In addition, most of the burst cited documents are focusing on the computer vision-based application [45-47] and the tracking of a component's location $[48,49]$ on-site. These findings suggest that locating and computer vision-related research are increased significantly in recent decades. They are possibly the recent trend of SCS research.

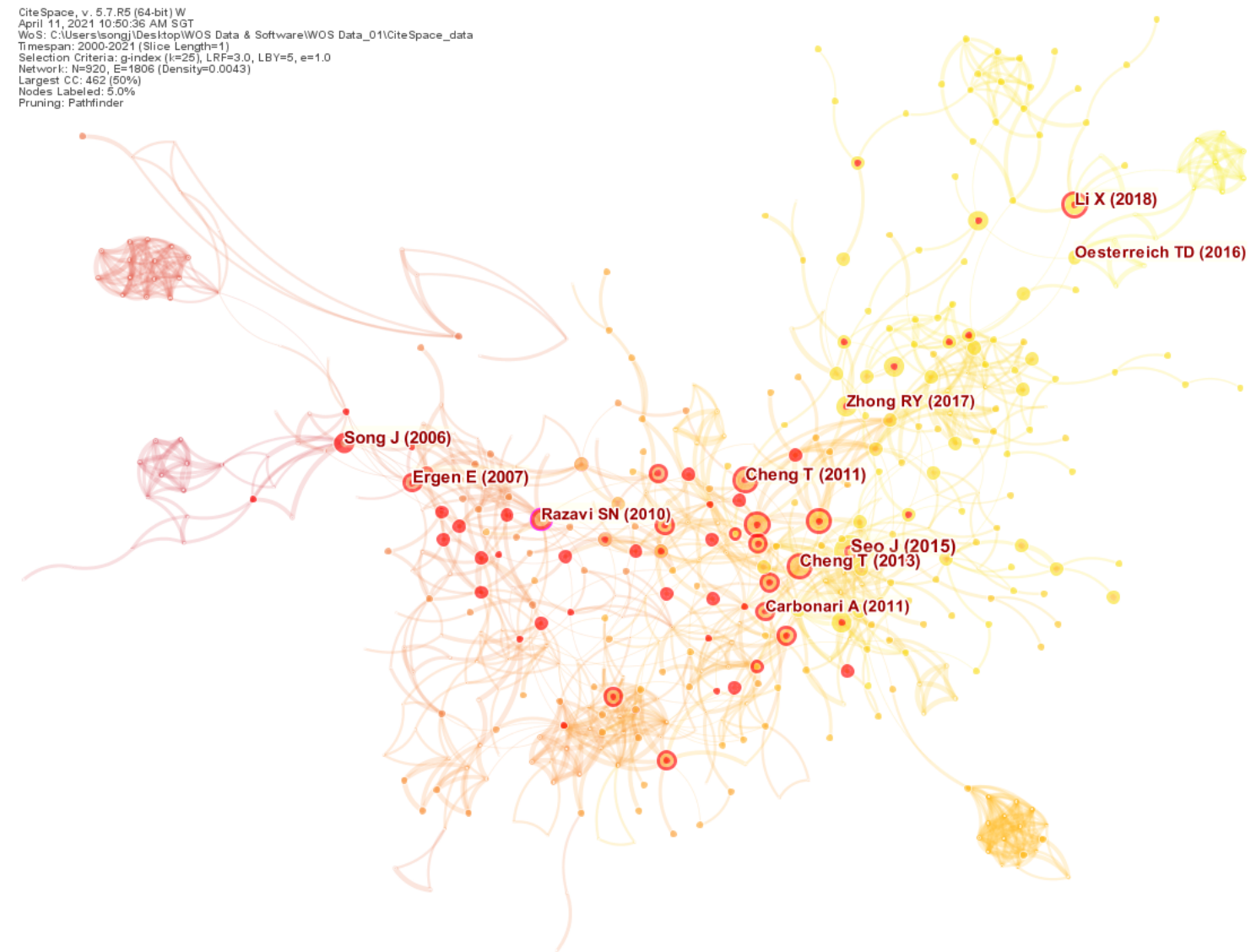

Figure 10. Network of document co-citation. 
In addition, a total of 229 clusters was detected in the document co-citation network in terms of keywords, and 13 clusters (as shown in Figure 11) among them were identified as significant by the log-likelihood ratio (LLR) method [50]. By calculating and ranking the significant value of frequently appearing words/phrases in an abstract, LLR can select the best labels for a cluster. The details of the 13 clusters were presented in Table 2, and the clusters are ranked by size (which indicting the number of the members).
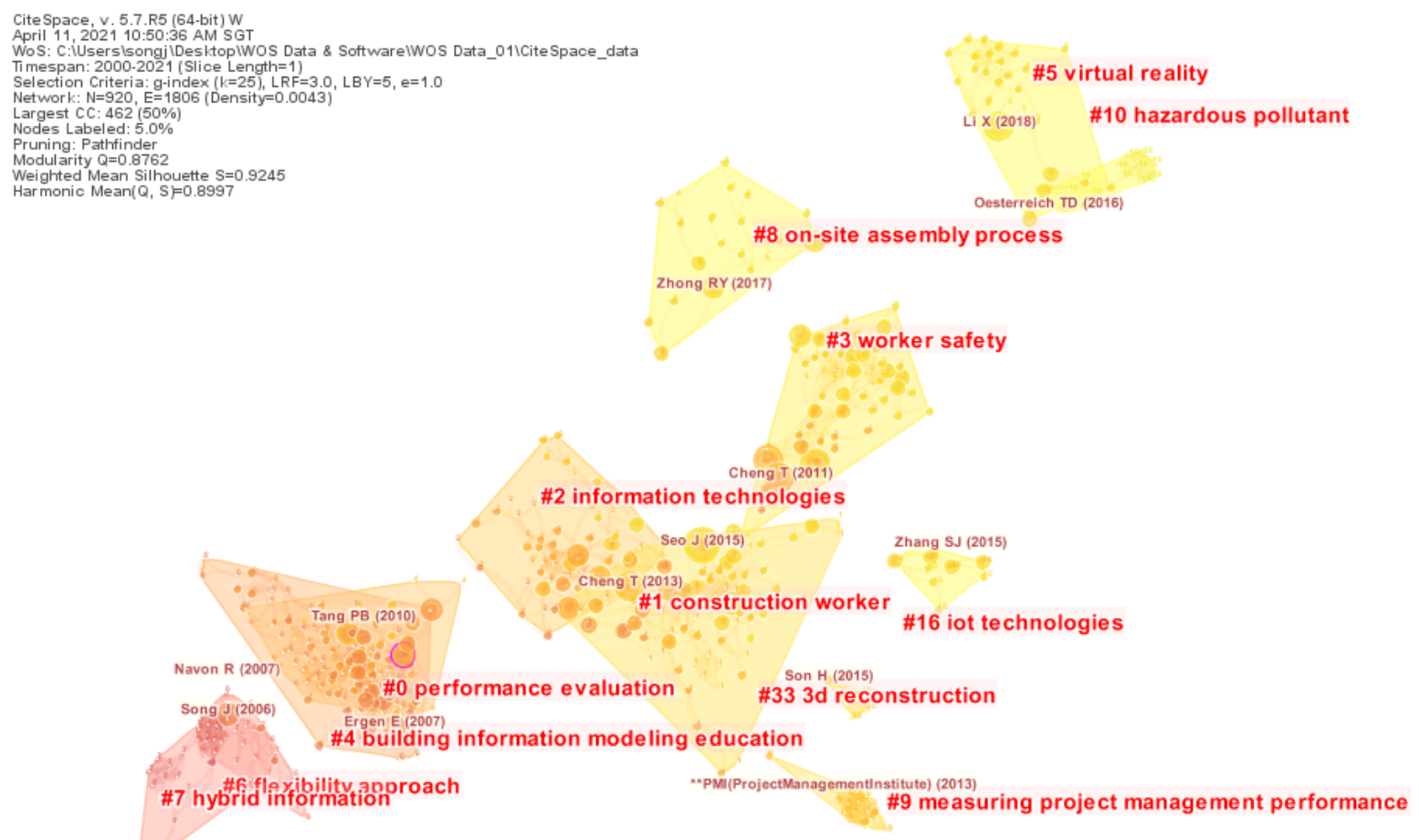

Figure 11. Clusters of knowledge domains on SCS research.

Table 2. Co-citation clusters of SCS research 2000-2021.

\begin{tabular}{cccccc}
\hline Cluster ID & Size & Silhouette & Label (LLR) & Mean (Year) & Representative Documents \\
\hline 0 & 81 & 0.900 & Performance evaluation & 2008 & [51] \\
\hline 1 & 70 & 0.926 & Construction worker & 2014 & {$[38]$} \\
\hline 2 & 58 & 0.854 & Information technologies & 2012 & [37] \\
\hline 3 & 56 & 0.909 & Worker safety & 2015 & {$[39]$} \\
\hline 4 & 52 & 0.892 & $\begin{array}{c}\text { Building information } \\
\text { modelling education }\end{array}$ & 2011 & {$[16]$} \\
\hline 5 & 28 & 0.980 & Virtual reality & 2017 & {$[52]$} \\
\hline 6 & 25 & 0.996 & Flexibility approach & 2006 & {$[41]$} \\
\hline 7 & 25 & 0.988 & Hybrid information & 2004 & {$[53]$} \\
\hline 8 & 21 & 0.957 & On-site assembly process & 2016 & {$[54]$} \\
\hline 9 & 18 & 0.985 & Measuring project & 2013 & {$[55]$} \\
\hline 10 & 14 & 0.994 & Hanagement performance & [56] \\
\hline 16 & 9 & 0.982 & IOT technologies & 2016 & {$[57]$} \\
\hline 33 & 5 & 0.996 & 3D reconstruction & 2014 &
\end{tabular}


Thus, cluster \#0 "performance evaluation" is the largest one with 81 members, followed by cluster \#1 "construction worker", cluster \#2 "information technologies", cluster \#3 "worker safety", cluster \#4 "building information modeling education", cluster \#5 "virtual reality", cluster \#6 "flexibility approach", cluster \#7 "hybrid information", cluster \#8 "on-site assembly process", cluster \#9 "measuring project management performance", cluster \#10 "hazardous pollutant", cluster \#16 "IoT technologies", and the smallest one is cluster \#33 “3D reconstruction" with only 5 members.

Silhouette is one of the structural metrics [50] in co-citation cluster analysis, and it is usually adopted to measure the average homogeneity of a cluster [58]. In this study, the silhouette score ranges from 0.854 to 0.996 , which suggests a higher consistency of the cluster members. In addition, the "Mean (Year)" in Table 2 is the average year of publications of a cluster. Generally, the inclusive publications could be the recently published papers if the mean is bigger, or vice versa.

As it can be concluded from Table 2 and Figure 11, the researchers' focus is gradually changing from traditional project performance related concerns (i.e., hybrid information (cluster \#7, mean-year $=2004$, silhouette $=0.957$ ), flexibility approach (cluster \#6, mean-year $=2006$, silhouette $=0.996$ ), performance evaluation (cluster \#0, mean-year $=2008$, silhouette $=0.900$ ), building information modelling education (cluster \#4, mean-year $=2011$, silhouette $=0.892)$, information technologies (cluster \#2, mean-year $=2012$, silhouette $=0.854)$, measuring project management performance (cluster \#9, mean-year $=2013$, silhouette $=0.985)$ ) to smart simulation scenes and applications (i.e., 3D re-construction (cluster \#33, meanyear $=2014$, silhouette $=0.996)$ and construction worker $($ cluster \#1, mean-year $=2014$, silhouette $=0.926)$, worker safety (cluster \#3, mean-year $=2015$, silhouette $=0.909)$, on-site assembly process (cluster \#8, mean-year $=2016$, silhouette $=0.957)$ and IOT technologies (cluster \#16, mean-year $=2016$, silhouette $=0.982)$, and hazardous pollutant (cluster $\# 10$, mean-year $=2017$, silhouette $=0.994) \&$ virtual reality $($ cluster $\# 5$, mean-year $=2017$, silhouette $=0.980)$ ).

Meanwhile, as can be seen in Figure 12, researchers in the construction industry are very interested in smart construction site technology's practical application in construction sites, and they are more concerned about the worker and construction scene-associated areas.

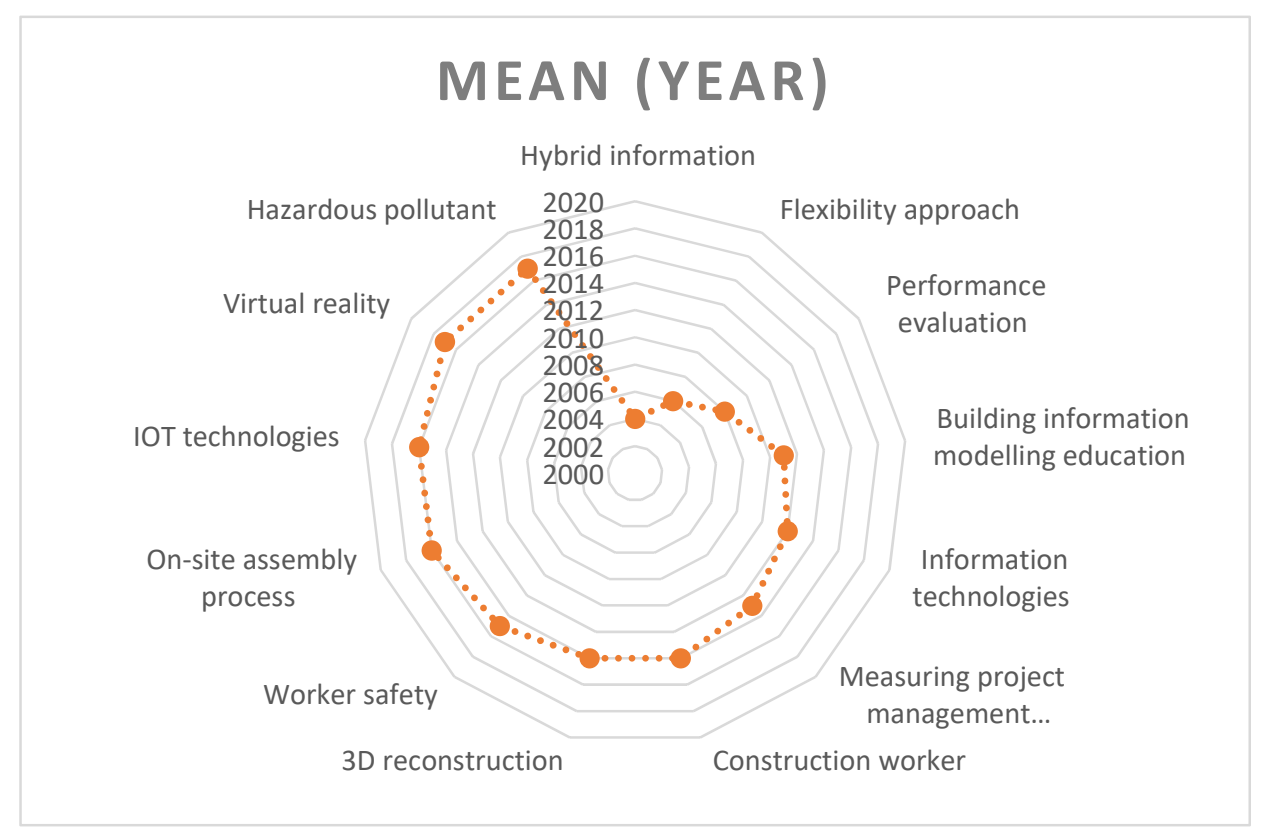

Figure 12. Research trend in terms of a cluster (mean year). 


\subsubsection{Journal Co-Citation Network}

As indicated in Figure 13, a journal co-citation network with 879 nodes and 6019 links was produced based on the analysis of references cited by the 2206 articles. It is used to detect the most cited journals with significant influences. The node size in this section represents the citation frequency of each journal, and Automation in Construction (frequency $=750$ ), Journal of Construction Engineering and Management (frequency $=617$ ), Journal of Computing in Civil Engineering (frequency $=484$ ), Journal of Management in Engineering (frequency = 316), Advanced Engineering Informatics (frequency $=289$ ), and International Journal of Project Management (frequency $=265$ ) are the top six most influential journals in terms of co-citation frequency.

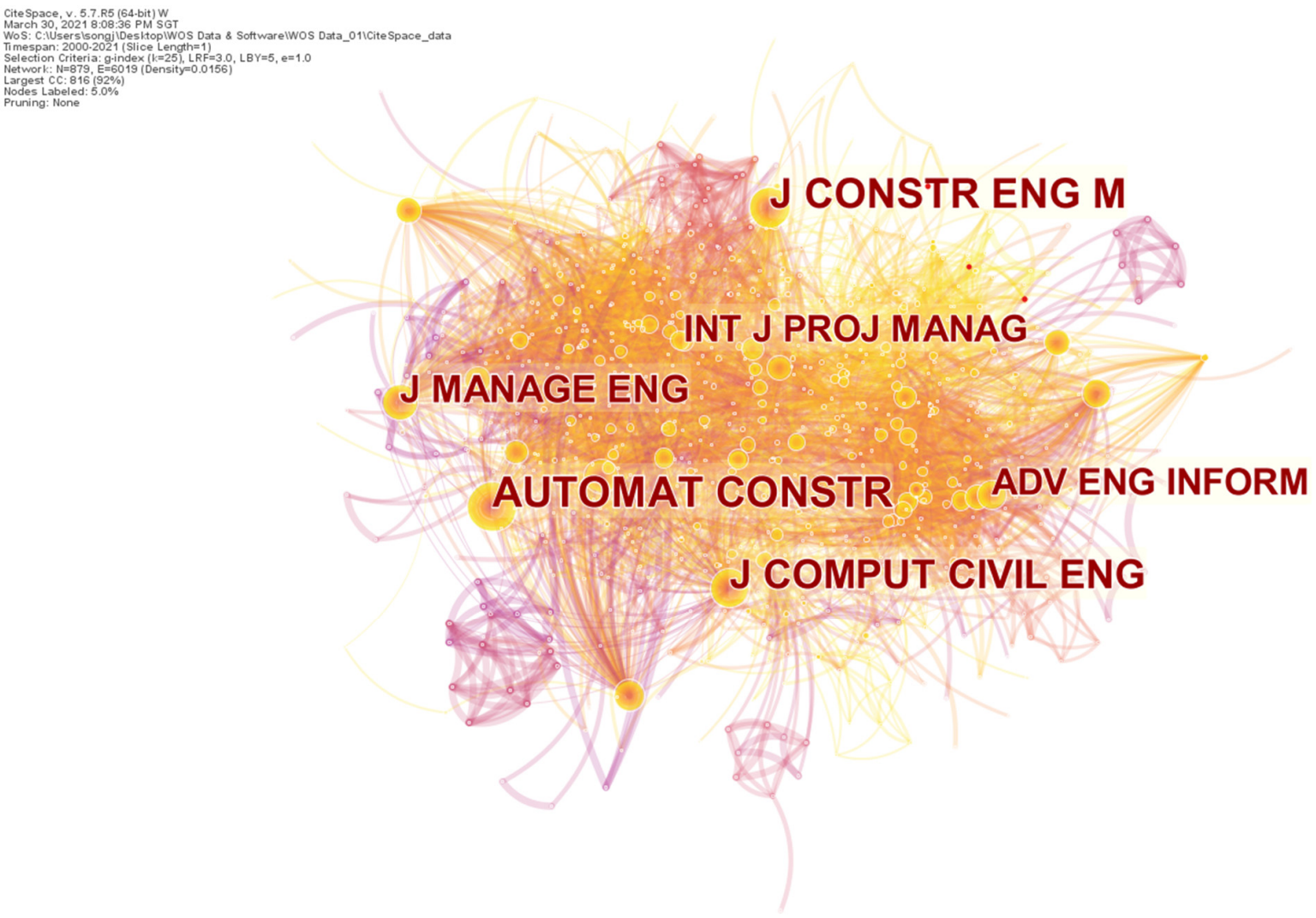

Figure 13. Journal co-citation network.

As stated earlier, the nodes inherited with higher betweenness centrality are highlighted by purple rings. In Figure 13, there are no journals highlighted with purple rings, which indicates that there are no significant links among the journals in different subject categories.

\section{Discussion}

This study aimed to perform a comprehensive review on the research status of smart construction sites in construction management and engineering, which has attracted many interests from researchers and practitioners. The main discussions of this study are presented as follows.

\subsection{Collaborations among Different Researchers/Institutions Are Not Close Enough}

Based on the results of collaboration network analysis, although some remarkable authors published many related papers (e.g., Teizer J, Heng L, Kim H., Carl T Hass), the cooperation among different authors is not common. For instance, the co-authorship network density is only 0.0018 , and additionally, there are only three obvious cooperation networks (e.g., the network of Heng Li, the network of Carl T Hass, and the network 
of Weisheng Lu). It is obvious that not all the most productive authors have built their collaboration network, which shows that the research on smart construction sites is still scattered and substantially still in the early stage of its development trajectory.

\subsection{The Leading Authors and Journals Are Beginning to Emerge}

Several high-productive and centralized journals and authors were identified in the past twenty years. For the author's co-citation network, the density of the author's cocitation network is 0.0104 , which is much greater than the co-authorships density. Thus, it can be considered that several centralized authors dominated the domain knowledge of smart construction site research and they are widely recognized as the expert in smart construction site research, such as Li Heng, Teizer J., Navon R., etc. Moreover, several core journals have published most of the smart construction site-related papers in this study, for instance, Automation in Construction, Journal of Construction Engineering and Management, Journal of Computing in Civil Engineering, and Journal of Management in Engineering, etc. Those journals also received high co-citation frequency and citation bursts in BIM-related research [22], which indicate their strong influences on the smart construction site research. Furthermore, it is interesting that the most co-cited document is not produced by the most cited coauthors. As it is presented in the document co-citation network section, [38-41,59] are the most co-cited documents; however, none authors of them occupy the most author co-citation and/or published most of the smart construction site related papers.

\subsection{Smart Construction Site Is More Than an Application of Technology in a Site}

Smart construction site is not just a traditional construction site equipped with information technology, but is also a new way of perceiving and understanding construction management and engineering through the light of innovation and productivity improvement [60]. For example, in the concept of Industry/Construction 4.0, there are many included technologies such as augmented reality, the internet of things, robotics, autonomous system, big data, and cybersecurity, but only fewer of them were adopted in construction management and engineering. Meanwhile, the application of smart construction sites also initiated the study of smart construction site management and benefits analysis, which is used to improve the productivity of construction sites [2]. Thus, researchers and practitioners cannot simply assume a smart construction site is a site equipped with Industry/Construction 4.0 technologies.

\subsection{Management Concerns Due to the Implementation of a Smart Construction Site}

Even though the implementation of a smart construction site can bring many benefits to a company, such as work efficiency, project productivity, and quality, safety, as well as much efficient of collaboration [2,21], the management issues that were initiated because of the implementation of smart construction site cannot be ignored. For instance, firstly, projects and/or companies have to deal with the relatively high costs of information technology hardware and systems; secondly, it will also require the improvement of working efficiency of staff for updating and obtaining information in a timely and easy manner, as well to the allocation optimization of machinery and various resources. Thirdly, there is also a need for better collaboration among site engineers, managers, and technology experts because no one can handle all the aspects alone. Last but not least, efforts must be allocated to employees and social-related issues because of the collision of smart technologies. Therefore, the management concerns that may raise should be understood and acknowledged to ensure a responsible construction engineering of future.

\section{Smart Construction Site Is Not Widely Acknowledged}

Despite the availability and popularity of many technologies and typical smart construction site cases in China [61], smart construction site is not widely acknowledged and adopted worldwide [55]. For example, according to Alaloul et al. [17], only 34\% of 
the respondents are aware and/or exposed to the emerging technologies in construction engineering. Thus, more efforts are deemed necessary to study how the smart construction site is being implemented and evaluated in every country.

\subsection{Staff's Involvement of Smart Construction Site}

As it was indicated by Edirisinghe [1], very fewer studies have researched the technologies from the user perspective. He believes that no matter how reliable and valid the smart technologies are, it will not make sense if the AEC projects managers do not accept and adopt it. Liu et al. [62] also believed user satisfaction is highly associated with the adoption and evaluation of new technologies. Hence, it is unavoidable to have site engineers and managers involved in the smart construction site implement process. This study believes there are three stages that site engineers and managers need to be involved in during the smart construction site application process. The first is prior to starting the development process in order to explore the site needs, and the second is during implementation to make sure the smart construction performance feeds the expectation on productivity. The third is to collect the feedback and keep satisfy the new coming requirements with patients. Meanwhile, as to the top management, the cost of a smart construction site is also not ignorable, and much attention should be paid to.

\subsection{Improve Productivity and Management Performance Is the Objective}

Although going digital is a necessary process to improving the construction industry's productivity and performance, smart construction is still in its infancy [63]. By comparing to the manufacturing industry, the rate of productivity development in the construction industry has been lower indeed [64]. As it is mentioned earlier, a smart construction site is not solely an application of smart technologies in a construction site, it is more about how to facilitate the construction engineering's productivity and management performance with the advantages of smart technologies. For instance, by leveraging the intent of things, sensors, and cyber-physical systems we can bi-directionally exchange information to monitor the asset's real-time status and pop-up alerts before the situation became serious. It could greatly reduce the costs of an incident. Thus, making smart technologies that improve site productivity and management performance should be one of the essential topics in the future.

\section{Conclusions}

With the trending of extensive application of IoT, AI, BIM, and Computer Vision, etc., in the construction field, the construction industry is about to enter its next generation-the digital skin and/or smart construction site generation. Modern construction management and engineering require smart technologies and new approaches for increasing safety and productivity, and process optimization. Fortunately, smart construction sites and the Industry/Construction 4.0 technologies emerging and bring benefits to it. By referring to 2206 publications collected from the Web of Science core collection database, this study reviewed and explored the status and trends of smart construction site-related research in a scientometric way.

Through the scientometric method, this study presented an overview of smart construction site publications from 2000 to 2020. The key contributors in terms of author, institution, country/region, and the most co-cited publication in terms of author, document, journal, as well as the research trends of topics, are presented and discussed in this study. As it is mentioned earlier, publications related to smart construction sites have been significantly increasing in last ten years. In addition, this study has provided the foundation for further research in the smart construction site area and has pointed out ethical and management-related issues that may arise in connection with the exploring adoption of smart technologies.

It is inevitable that this study faces limitations. For instance, the timespan and the explosive revolution and integration of technologies. As it is indicated by Forcael et al. [60], 
studies on smart technology topics should be conducted at least every 3 years, thus it is expected that the applicability of this study might be limited to a specific period. Meanwhile, the AEC industry is experiencing an explosive exposure to new concepts, technologies, and new approaches, which may bring a new conceptualization of the word smart construction site in the future, which may lead to the question of applicability of the conclusions, while overall, this study could provide valuable information to both scholars and practitioners in smart construction site-associated areas. For instance, to the scholars, this study could facilitate them to effectively discover the most productive authors and the most influential literature; to the practitioners, this study could help them to effectively identify the latest frontier in the field of the smart construction site, then enhance and/or develop new product to expanding their future market. Last, but not least, this study highlighted seven less noticeable topics associated with the implementation and management of smart construction sites in the AEC industry. It is foreseeable that each of the seven topics will attract much more attention from practitioners and scholars in the future. Finally, this study also expanded the methodology for smart construction site-related research.

Author Contributions: Conceptualization, J.S. and H.L.; methodology, J.S.; software, Liuhonglei; validation, G.W.; formal analysis, G.W.; writing—original draft preparation, J.S.; writing—review and editing, J.S., G.W., H.L.; visualization, H.L.; funding acquisition, H.L. All authors have read and agreed to the published version of the manuscript. Please turn to the CRediT taxonomy for the term explanation.

Funding: This research received no external funding.

Data Availability Statement: All the data this paper used are extracted from Web of Science Core Database.

Conflicts of Interest: The authors declare no conflict of interest.

\section{References}

1. Edirisinghe, R. Digital skin of the construction site. Eng. Constr. Archit. Manag. 2019, 26, 184-223. [CrossRef]

2. McCabe, B.Y.; Hamledari, H.; Shahi, A.; Zangenh, P.; Azar, E.R. Roles, Benefits, and Challenges of Using UAVs for Indoor Smart Construction Applications. Comput. Civ. Eng. 2017, 2017, 349-357.

3. Hammad, A.; Vahdatikhaki, F.; Zhang, C. Towards the smart construction site: Improving productivity and safety of construction projects using multi-agent systems, real-time simulation and automated machine control. In Proceedings of the 2012 Winter Simulation Conference (WSC), Berlin, Germany, 9-12 December 2012.

4. Kim, S.-J.; Ok, H.; Kim, T.-H. Mobile App Development for Smart Construction Site Work Processing. In Proceedings of the 9th International Conference on Information Management and Engineering; Association for Computing Machinery: New York, NY, USA, 2017.

5. Rossi, A.; Vila, Y.; Lusiani, F.; Barsotti, L.; Sani, L. Embedded smart sensor device in construction site machinery. Comput. Ind. 2019, 108, 12-20. [CrossRef]

6. Jin, R.; Zou, Y.; Gidado, K.; Ashton, P.; Paiting, N. Scientometric analysis of BIM-based research in construction engineering and management. Eng. Constr. Archit. Manag. 2019, 26, 1750-1776. [CrossRef]

7. Kang, Y.; O’Brien, W.; Thomas, S. Impact of information technologies on performance: Cross study comparison. J. Constr. Eng. Manag. 2008, 134, 852-863. [CrossRef]

8. Hwang, S. Ultra-wide band technology experiments for real-time prevention of tower crane collisions. Autom. Constr. 2012, 22, 545-553. [CrossRef]

9. Pan, Y.; Zhang, L. Roles of artificial intelligence in construction engineering and management: A critical review and future trends. Autom. Constr. 2021, 122, 103517. [CrossRef]

10. Jiang, W.; Ding, L.; Zhou, C. Cyber physical system for safety management in smart construction site. Eng. Constr. Archit. Manag. 2020, 28, 788-808. [CrossRef]

11. Štefanič, M.; Stankovski, V. A review of technologies and applications for smart construction. Civil Eng. 2019, $172,83-87$. [CrossRef]

12. Kozlovska, M.; Klosova, D.; Strukova, Z. Impact of Industry 4.0 Platform on the Formation of Construction 4.0 Concept: A Literature Review. Sustainability 2021, 13, 2683. [CrossRef]

13. Boton, C.; Rivest, L.; Ghnaya, O.; Chouchen, M. What is at the Root of Construction 4.0: A systematic review of the recent research effort. Arch. Comput. Methods Eng. 2021, 28, 2331-2350. [CrossRef]

14. Newman, C.; Edwards, D.; Martek, I.; Lai, J.; Thwala, W.D.; Rillie, I. Industry 4.0 deployment in the construction industry: A bibliometric literature review and UK-based case study. Smart Sustain. Built. Environ. 2020. ahead-of-print. [CrossRef] 
15. Zabidin, N.S.; Belayutham, S.; Ibrahim, C.K.I.C. A bibliometric and scientometric mapping of Industry 4.0 in construction. J. Inf. Technol. Constr. 2020, 25, 287-307. [CrossRef]

16. Li, X.; Yi, W.; Chi, H.; Wang, X.; Chan, A. A critical review of virtual and augmented reality (VR/AR) applications in construction safety. Autom. Constr. 2018, 86, 150-162. [CrossRef]

17. Alaloul, W.S.; Liew, M.S.; Zawawi, N.A.W.A.; Kennedy, I.B. Industrial Revolution 4.0 in the construction industry: Challenges and opportunities for stakeholders. Ain Shams Eng. J. 2020, 11, 225-230. [CrossRef]

18. Mehta, B.S. Trouble in the Making? The Future of Manufacturing-Led Development; World Bank Publications: Washington, DC, USA, 2017.

19. Sawhney, A.; Riley, M.; Irizarry, J. Construction 4.0: Introduction and Overview. In Construction 4.0; Routledge: London, UK, 2020; pp. 3-22.

20. Martinez, P.; Ai-Hussein, M.; Ahmad, R. A scientometric analysis and critical review of computer vision applications for construction. Autom. Constr. 2019, 107, 102947. [CrossRef]

21. El-Sayegh, S.; Romdhane, L.; Manjikian, S. A critical review of 3D printing in construction: Benefits, challenges, and risks. Arch. Civ. Mech. Eng. 2020, 20, 1-25. [CrossRef]

22. Zhao, X. A scientometric review of global BIM research: Analysis and visualization. Autom. Constr. 2017, 80, 37-47. [CrossRef]

23. Chen, C.; Rachael, D.; Meen, C. Emerging trends and new developments in regenerative medicine: A scientometric update (2000-2014). Expert Opin. Biol. Ther. 2014, 14, 1295-1317. [CrossRef]

24. Olawumi, T.O.; Chan, D.W. A scientometric review of global research on sustainability and sustainable development. J. Clean. Prod. 2018, 183, 231-250. [CrossRef]

25. Xue, J.; Shen, G.Q.; Yang, R.J.; Wu, H.; Li, X.; Lin, X.; Xue, F. Mapping the knowledge domain of stakeholder perspective studies in construction projects: A bibliometric approach. Int. J. Proj. Manag. 2020, 38, 313-326. [CrossRef]

26. Chen, C. CiteSpace: A Practical Guide for Mapping Scientific Literature; Nova Science Publishers: Hauppauge, NY, USA, 2016.

27. Hjørland, B.; Albrechtsen, H. Toward a new horizon in information science: Domain-analysis. J. Am. Soc. Inf. Sci. 1995, 46, 400-425. [CrossRef]

28. Katz, J.; Martin, B. What is Research Collaboration? Res. Policy 1997, 26, 1-18. [CrossRef]

29. Wuchty, S.; Jones, S.; Uzzi, B. The Increasing Dominance of Teams in Production of Knowledge. Science 2007, 316, 1036. [CrossRef] [PubMed]

30. Zhang, J.; Yu, Q.; Zheng, F.; Long, C.; Lu, Z.; Duan, Z. Comparing keywords plus of WOS and author keywords: A case study of patient adherence research. J. Assoc. Inf. Sci. Technol. 2016, 67, 967-972. [CrossRef]

31. Wei, F.; Zhang, G. A Document Co-Citation Analysis Method for Investigating Emerging Trends and New Developments: A Case of Twenty-Four Leading Business Journals; University of Boras: Boras, Sweden, 2020.

32. Small, H. Co-citation in the scientific literature: A new measure of the relationship between two documents. J. Am. Soc. Inf. Sci. 1973, 24, 265-269. [CrossRef]

33. Teizer, J.; Allread, B.S.; Fullerton, C.E.; Hinze, J. Autonomous pro-active real-time construction worker and equipment operator proximity safety alert system. Autom. Constr. 2010, 19, 630-640. [CrossRef]

34. Li, H.; Ma, Z.; Shen, Q.; Kong, S. Virtual experiment of innovative construction operations. Autom. Constr. 2003, 12, 561-575. [CrossRef]

35. Golparvar-Fard, M.; Peña-Mora, F.; Savarese, S. Integrated Sequential As-Built and As-Planned Representation with D4AR Tools in Support of Decision-Making Tasks in the AEC/FM Industry. J. Constr. Eng. Manag. 2011, 137, 1099-1116. [CrossRef]

36. Navon, R.; Berkovich, O. An automated model for materials management and control. Constr. Manag. Econ. 2006, 24, 635-646. [CrossRef]

37. Cheng, T.; Teizer, J. Real-time resource location data collection and visualization technology for construction safety and activity monitoring applications. Autom. Constr. 2013, 34, 3-15. [CrossRef]

38. Seo, J.; Han, S.H.; Lee, S.H.; Kim, H. Computer vision techniques for construction safety and health monitoring. Adv. Eng. Inform. 2015, 29, 239-251. [CrossRef]

39. Cheng, T.; Venugopal, M.; Teizer, J.; Vela, P. Performance evaluation of ultra wideband technology for construction resource location tracking in harsh environments. Autom. Constr. 2011, 20, 1173-1184. [CrossRef]

40. Ergen, E.; Akinci, B.; Sacks, R. Tracking and locating components in a precast storage yard utilizing radio frequency identification technology and GPS. Autom. Constr. 2007, 16, 354-367. [CrossRef]

41. Song, J.; Haas, C.T.; Caldas, C.; Ergen, E.; Akinci, B. Automating the task of tracking the delivery and receipt of fabricated pipe spools in industrial projects. Autom. Constr. 2006, 15, 166-177. [CrossRef]

42. Razavi, S.N.; Haas, C.T. Multisensor data fusion for on-site materials tracking in construction. Autom. Constr. 2010, 19, 1037-1046. [CrossRef]

43. Jaselskis, E.J.; El-Misalami, T. Implementing Radio Frequency Identification in the Construction Process. J. Constr. Eng. Manag. 2003, 129, 680-688. [CrossRef]

44. Yagi, J.; Ariai, E.; Arai, T. Parts and packets unification radio frequency identification (RFID) application for construction. Autom. Constr. 2005, 14, 477-490. [CrossRef]

45. Gong, J.; Caldas, C.H. Computer Vision-Based Video Interpretation Model for Automated Productivity Analysis of Construction Operations. J. Comput. Civ. Eng. 2010, 24, 252-263. [CrossRef] 
46. Dimitrov, A.; Golparvar-Fard, M. Vision-based material recognition for automated monitoring of construction progress and generating building information modeling from unordered site image collections. Adv. Eng. Inform. 2014, 28, 37-49. [CrossRef]

47. Fang, Q.; Li, H.; Luo, X.; Ding, L.; Luo, H.; Rose, T.; An, W. Detecting non-hardhat-use by a deep learning method from far-field surveillance videos. Autom. Constr. 2018, 85, 1-9. [CrossRef]

48. Khoury, H.M.; Kamat, V.R. Evaluation of position tracking technologies for user localization in indoor construction environments. Autom. Constr. 2009, 18, 444-457. [CrossRef]

49. Kanan, R.; Elhassan, O.; Bensalem, R. An IoT-based autonomous system for workers' safety in construction sites with real-time alarming, monitoring, and positioning strategies. Autom. Constr. 2018, 88, 73-86. [CrossRef]

50. Chen, C.; Ibekwe-Sanjuan, F.; Hou, J. The structure and dynamics of cocitation clusters: A multiple-perspective cocitation analysis J. Am. Soc. Inf. Sci. Technol. 2010, 61, 1386-1409. [CrossRef]

51. Tang, P.; Huber, D.; Akinci, B.; Lipman, R.; Lytle, A. Automatic reconstruction of as-built building information models from laser-scanned point clouds: A review of related techniques. Autom. Constr. 2010, 19, 829-843. [CrossRef]

52. Navon, R.; Sacks, R. Assessing research issues in Automated Project Performance Control (APPC). Autom. Constr. 2007, 16, 474-484. [CrossRef]

53. Zhong, R.Y.; Peng, Y.; Xue, F.; Fang, J.; Zou, W.; Luo, H.; Huang, G.Q. Prefabricated construction enabled by the Internet-of-Things. Autom. Constr. 2017, 76, 59-70. [CrossRef]

54. Rose, K.H. A Guide to the Project Management Body of Knowledge (PMBOK ®Guide)-Fifth Edition. Proj. Manag. J. 2013, 3, e1. [CrossRef]

55. Oesterreich, T.D.; Teuteberg, F. Understanding the implications of digitisation and automation in the context of Industry 4.0: A triangulation approach and elements of a research agenda for the construction industry. Comput. Ind. 2016, 83, 121-139. [CrossRef]

56. Zhang, S.; Teizer, J.; Pradhananga, N.; Eastman, C.M. Workforce location tracking to model, visualize and analyze workspace requirements in building information models for construction safety planning. Autom. Constr. 2015, 60, 74-86. [CrossRef]

57. Son, H.; Bosché, F.; Kim, C. As-built data acquisition and its use in production monitoring and automated layout of civil infrastructure. Adv. Eng. Inform. 2015, 29, 172-183. [CrossRef]

58. Rousseeuw, P. Silhouettes: A graphical aid to the interpretation and validation of cluster analysis. J. Comput. Appl. Math. 1987, 20, 53-65. [CrossRef]

59. Cheng, T.; Teizer, J.; Migliaccio, G.C.; Gatti, U.C. Automated task-level activity analysis through fusion of real time location sensors and worker's thoracic posture data. Autom. Constr. 2013, 29, 24-39. [CrossRef]

60. Forcael, E.; Ferrari, I.; Opazo-Vega, A.; Pulido-Arcas, J.A. Construction 4.0: A Literature Review. Sustainability 2020, $12,9755$. [CrossRef]

61. You, Z.; Feng, L. Integration of industry 4.0 related technologies in construction industry: A framework of cyber-physical system. IEEE Access 2020, 8, 122908-122922. [CrossRef]

62. Liu, H.; Song, J.; Wang, G. Development of a tool for measuring building information modeling (BIM) user satisfaction-method selection, scale development and case study. Eng. Constr. Archit. Manag. 2020, 27, 2409-2427. [CrossRef]

63. Yang, Z.; Wang, Y.; Sun, C. Emerging information technology acceptance model for the development of smart construction system. J. Civ. Eng. Manag. 2018, 24, 457-468. [CrossRef]

64. Ghasemi, P.S.P.; Chong, H.-Y. Pathways for the improvement of construction productivity: A perspective on the adoption of advanced techniques. Adv. Civ. Eng. 2020, 5170759. [CrossRef] 